Published in final edited form as:

Won, J. Y., Gochev, G., Ulaganathan, V., Krägel, J., Aksenenko, E., Fainerman, V., et al. (2017). Effect of Solution pH on the Adsorption of BLG at the Solution/Tetradecane Interface.

Colloids and Surfaces A: Physicochemical and Engineering Aspects, 519, 161-167.

doi:10.1016/j.colsurfa.2016.05.042.

\title{
Effect of Solution pH on the Adsorption of BLG at the Solution/Tetradecane Interface
}

\author{
J.Y. Won, G.G. Gochev, V. Ulaganathan, J. Krägel, E.V. Aksenenko,
}

V.B. Fainerman, R. Miller
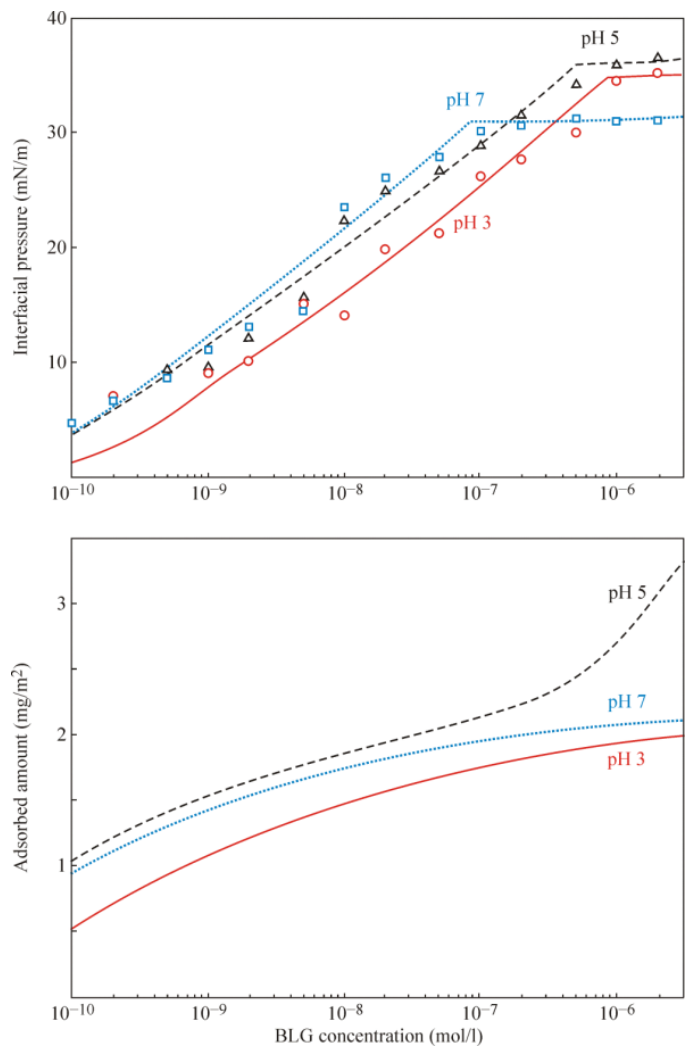

Surface properties of $10 \mathrm{mM}$ buffered BLG solutions with different $\mathrm{pH}$ values at the W/TD interface.

Top, surface pressure isotherm; bottom, adsorption isotherm.

Symbols, experimental points; Lines: best fit of the results calculated using the diffusion controlled adsorption model to the experimental data. 0 , red solid line, $\mathrm{pH} 3 ; \Delta$, black dashed line, $\mathrm{pH} 5$; $\square$, blue dotted line, $\mathrm{pH} 7$. 
Effect of Solution $\mathrm{pH}$ on the Adsorption of BLG at the Solution/Tetradecane Interface

J.Y. Won ${ }^{1 *}$, G.G. Gochev ${ }^{1,2}$, V. Ulaganathan ${ }^{1}$, J. Krägel ${ }^{1}$, E.V. Aksenenko ${ }^{3}$, V.B. Fainerman ${ }^{4}$, R. Miller ${ }^{1}$

${ }^{1}$ Max Planck Institute of Colloids and Interfaces, D-14424 Golm, Germany

${ }^{2}$ Institute of Physical Chemistry, Bulgarian Academy of Sciences, 1113 Sofia, Bulgaria

${ }^{3}$ Institute of Colloid Chemistry and Chemistry of Water, 03680 Kyiv (Kiev), Ukraine

${ }^{4}$ Medical University Donetsk, 83003 Donetsk, Ukraine

* Corresponding author. 


\section{HIGHLIGHTS}

- The surface pressure isotherms at the W/A surface exhibit much steeper run than interfacial pressure at the W/TD interface.

- The adsorption kinetics of BLG molecules show that it is required the shortest time to adapt the conformation at the interface at $\mathrm{pH} 5$, while the re-conformation times are larger at $\mathrm{pH} 3$ and $\mathrm{pH} 7$.

- The total adsorbed amount of BLG at pH 3 is significantly less than pH 5 and 7 at the bulk concentrations of $\mathrm{C}_{\mathrm{BLG}}<10^{-6} \mathrm{~mol} / \mathrm{l}$ at the W/TD interface.

- The dependences of the interfacial pressure and the area per molecule on the adsorbed amount of BLG at the W/TD interface show the similar trend as those of W/A surface, therefore it is not the total adsorbed amount leading to the high interfacial pressure values but the interfacial structure resulting from a strong interaction between BLG and the oil molecules at the interface.

- By assuming an additional change in the surface activity of the adsorbing BLG molecules, the new mixed model describes the experimental data quantitatively while the pure diffusion controlled adsorption model leads to a rather bad description of the experiments. 
Abstract

Using drop profile analysis tensiometry the adsorption dynamics and the equilibrium equation of state of $\beta$-lactoglobulin (BLG) at the water/tetradecane (W/TD) interface are studied at $\mathrm{pH}$ 3, 5 and 7. The data are well described by a thermodynamic adsorption model using almost identical model parameters for all three $\mathrm{pH}$ values except for the surface activity coefficient. The surface pressure isotherms at the water/air (W/A) surface exhibit much steeper run than interfacial pressure at the W/TD interface for any of the studied cases at $\mathrm{pH} 3,5$ and 7 , and the calculated adsorption isotherm data point at smaller adsorbed amounts for these $\mathrm{pH}$. This seems to be in contrast to the much larger interfacial pressure changes reached at high BLG concentrations at the W/TD interface, which are almost three times higher than those at the W/A surface. The observations can be explained by a strong interaction between BLG and the oil molecules at the interface.

The dynamic interfacial tensions can be adequately described by a mixed adsorption model, assuming a diffusional transport of the protein molecules in the aqueous bulk phase and an adsorption mechanism which assumes a change of the adsorption activity parameter in dependence of the interfacial coverage.

\section{Keywords}

$\beta$-lactoglobulin, water-tetradecane interface, drop profile analysis tensiometry, dynamic interfacial tensions, equation of state, $\mathrm{pH}$ effect 


\section{Introduction}

In many modern technologies proteins play an important role. In particular for the production of various food products proteins are essential ingredients. For the tailored application of proteins and the optimum solution conditions systematic fundamental studies are essential. Although proteins do not decrease the surface or interfacial tensions in foam or emulsion systems, their presence is essential for the stabilization of these liquid colloidal systems. Due to the nature of the corresponding technologies, not only the equilibrium but also the dynamic interfacial properties of proteins are of great importance $[0,0]$.

The adsorption of proteins at water/oil interfaces is a process which does not only depend on the protein's bulk concentration. Due to their nature, protein molecules adsorb at an interface and upon contact with the hydrophobic phase can change their conformation. This can change the dynamics of the adsorption process, response of the interfaces to mechanic perturbations, and even the overall structure of the formed interfacial layers. The so-called induction time, for example, depends not only on protein bulk concentration [0-0] but also on the $\mathrm{pH}[0-0]$ and ionic strength of the solution [0].

In this respect, the $\mathrm{pH}$ and the ionic strength of the protein solution have a tremendous impact on the structure and interaction of protein molecules in the bulk and consequently at interfaces. These effects were studied for several proteins at the water/air (W/A) surface for example in $[0,0-0]$, while only few special systematic investigations on $\beta$-lactoglobulin (BLG) solution surfaces were performed regarding the adsorption kinetics [0] and the dilational visco-elasticity [0]. Interesting experiments with aqueous BLG solutions at different $\mathrm{pH}$ and ionic strength had been dedicated to the behaviour of rising bubbles [0], the local velocity profile of which allows, in particular at very low protein concentrations, to look into the surface layer structures.

As mentioned above, proteins have not only to be transported to the interface in order to get adsorbed, but upon contact with the interface their conformation may be changed. In [0], Song and Damodaran discussed that changes in the orientation of globular protein molecules can influence the adsorption kinetics. However, this kind of mechanism applies only to short adsorption time data. Recently, we discussed the mechanism of BLG adsorption in terms of changes in the surface activity due to the contact of the protein molecules with the hydrophobic oil phase [0]. To do so, we assume that the parameter in the equation of state, responsible for reflecting the surface activity of the adsorbing molecules, is changing as a 
function of the surface coverage. We have shown that the agreement of this theoretical approach with experimental data for BLG solutions at $\mathrm{pH} 3$ and low fixed ionic strength was very good [0].

The present work is dedicated to the surface pressure isotherms for buffered (10 mM) BLG solutions at three different $\mathrm{pH}$ values $(3,5$ and 7$)$. Based on these isotherm data, the dynamic surface pressure dependencies $\Pi(\mathrm{t})$ are analysed using the new theoretical approach given in [0]. The obtained adsorption parameters are discussed in terms of the $\mathrm{pH}$ effect and the particular impact of tetradecane as the adjacent oil phase.

\section{Materials and Methods}

The $\beta$-lactoglobulin used in this work had a purity of $89 \%$ and a molecular weight $18300 \mathrm{Da}$. It was prepared from whey protein isolate as described in [0]. To eliminate disturbing lowmolecular weight impurities, the stock solutions were purified with charcoal. Activated charcoal was added to a BLG solution in a mass ratio of $1: 3$, the resulting suspension stirred over $20 \mathrm{~min}$, and finally the solution was filtered with a $0.45 \mu \mathrm{m}$ pore size filter [0].

The BLG stock solutions were prepared for each $\mathrm{pH}$ value using a $\mathrm{Na}_{2} \mathrm{HPO}_{4} / \mathrm{Citric}$ Acid/Milli-Q water buffer with an ionic strength of $\mathrm{C}_{\text {buff }}=10 \mathrm{mM}$, and stored in a fridge at 5 ${ }^{\circ} \mathrm{C}$ for a maximum of 3 days. The respective measurement solutions were then prepared by dilution of the stock solution right before each experiment. The buffer solutions were prepared always with Milli-Q water and they had a surface tension of $72.5 \mathrm{mN} / \mathrm{m}$ at room temperature of $21^{\circ} \mathrm{C}$.

The n-tetradecane (TD) was purchased from Alfa Aesar and purified first by distillation. Afterwards the TD was washed several times with Florisil until the measured interfacial tension to the pure buffer solution was independent of time and had a value of $52.5 \mathrm{mN} / \mathrm{m}$.

The dynamic interfacial tensions were measured with the drop profile analysis tensiometer PAT-1 (SINTERFACE Technologies, Germany) according to the procedures given in [0]. The typical size of TD drops formed in the aqueous BLG solutions was $10 \mu$ l having a surface area of about $21 \mathrm{~mm}^{2}$. Before a drop was quickly formed to be used in the measurements several drops were first formed and discarded in order to have a drop with very fresh surface at the beginning of the experiment $t=0$. All measurements were performed over a time period of about $80000 \mathrm{~s}$, which is almost one day. At certain moments harmonic drop oscillations 
were generated. Such experiments are suitable for the determination of the dilational viscoelasticity data, however, we will report on these results only in a forthcoming paper.

The equilibrium interfacial pressure is defined by $\Pi=\gamma_{0}-\gamma_{\mathrm{eq}}$ with $\gamma_{0}=52.5 \mathrm{mN} / \mathrm{m}$ for the pure buffer/tetradecane (W/TD) interface. For low protein concentrations the $\gamma_{\mathrm{eq}}$ value was obtained via the extrapolation of measured dynamic interfacial tension values to infinite time $t$ $\rightarrow \infty$ in $\Pi v s \mathrm{t}^{-1 / 2}$ plots, while for higher concentrations the equilibration occurred in about 80000 s. The dynamic surface pressures $\Pi(t)$ are just the differences between the measured dynamic interfacial tensions $\gamma_{0}$ and $\gamma(\mathrm{t})$.

\section{Theoretical Model}

There exist various theoretical models to describe layers of polymers adsorbed at liquid interfaces. In the most frequently referred study by Graham and Phillips [0-0] no specific adsorption models for proteins existed yet in literature and the authors used the equation proposed by Singer [0] for analysing the measured surface pressure isotherms. Such rather general model for polymers, however, cannot take any specific properties of proteins into account. Only in 1991 Joos and Serrien [0] proposed to make use of the principle of Braun-Le Châtelier for describing liquid interfacial layers. This principle describes the coexistence of adsorbed molecules at an interface in different states controlled by the surface coverage or surface pressure. The model derived in [0] is based on this principle and is suitable to describe the adsorption of protein molecules over a broad concentration range. The model assumes that adsorbed protein molecules can exist in the states with a molar area varying from a maximum value $\left(\omega_{\mathrm{m}}\right)$ at very low surface coverage $\theta$ (or low surface pressure) to a minimum value $\left(\omega_{1}>\right.$ $\left.\omega_{0}\right)$ at high surface coverage. The equations of this adsorption model are explained in detail in [0]; here we present these equations only to the extent which is necessary for the purpose of the present article.

The equation of state reads:

$$
-\frac{\Pi \omega_{0}}{\mathrm{RT}}=\ln (1-\theta)+\theta\left(1-\frac{\omega_{0}}{\omega}\right)+\mathrm{a} \theta^{2}
$$

Here $\mathrm{R}$ is the gas law constant, $\mathrm{T}$ is the temperature, $\omega$ is the average molar area of protein, $\mathrm{a}$ is the protein intermolecular interaction parameter, $\omega_{0}$ is the molar area increment between two "neighbouring" states, which is approximately equal to the molar area of an adsorbed protein segment or a water molecule. 
The adsorption isotherm for adsorption state of the protein in state 1 reads:

$$
\mathrm{b}_{1} \mathrm{c}_{\mathrm{S} / \mathrm{S}}=\frac{\omega \Gamma_{1}}{(1-\theta)^{\omega_{1} / \omega}} \exp \left(-2 \mathrm{a} \frac{\omega_{1}}{\omega} \theta\right)
$$

where $c_{S / S}$ is the subsurface concentration of protein, and $\Gamma_{1}$ and $\omega_{1}$ are the "partial" adsorption and molar area of protein in the 1-st state, i.e. the state with smallest molar area. Note also that the adsorption activity coefficient of the j-th state is related to that of the 1-st state via the parameter $\alpha: b_{j}=\left(\omega_{j} / \omega\right)^{\alpha} \cdot b_{1}$, which reflects the fact that the conformational changes lead to the changes in the surface activity of the adsorbed protein molecules. This fact results in the equation which expresses the average molar area via the partial areas of protein molecule in different states:

$$
\omega=\frac{\sum_{j=1}^{n} \omega_{j}\left(\frac{\omega_{j}}{\omega_{1}}\right)^{\alpha} \exp \left\{\frac{\omega_{j}-\omega_{1}}{\omega} \ln (1-\theta)\right\}}{\sum_{j=1}^{n}\left(\frac{\omega_{j}}{\omega_{1}}\right)^{\alpha} \exp \left\{\frac{\omega_{j}-\omega_{1}}{\omega} \ln (1-\theta)\right\}}
$$

It was also assumed in [0] that there exists certain critical bulk concentration, and hence the critical surface pressure $\Pi^{*}$ above which a formation of small aggregates in the monolayer takes place. The adsorption isotherm in this post-critical concentration range is the same as in the pre-critical regime, while the equation of state becomes dependent on the aggregation number $\mathrm{n}_{\mathrm{a}}$ :

$$
\Pi=\Pi *\left(1+\frac{1}{\mathrm{n}_{\mathrm{a}}} \frac{\Gamma-\Gamma^{*}}{\Gamma^{*}}\right)
$$

Also, to account for a multilayer adsorption, an additional adsorption activity coefficient $\mathrm{b}_{\mathrm{X}}$ was introduced, which can be referred to as the secondary layer constant. The value of this parameter is much lower than $b_{1}$. This assumption was successfully applied for the theoretical description of BLG adsorption layers at the water/air interface [0]. For the total adsorption in $\mathrm{m}$ layers $\Gamma_{\Sigma}$ is calculated as:

$$
\Gamma_{\Sigma}=\Gamma \sum_{j=1}^{m}\left(\frac{b_{X} c}{1+b_{X} c}\right)^{j-1}
$$

where $\Gamma=\theta / \omega$ is the adsorption of protein in the first layer. 
In this study we are interested in the temporal evolution of the adsorption system, i.e. the time dependence of surface tension of adsorbed layer. This behaviour is governed by the diffusion kinetics. For proteins adsorbing at liquid/fluid interfaces, a simple diffusion model does not apply, although in many publications it was used. For example, Graham and Phillips [0] used a simplified approach based on the account for the first term only in the right hand side of Ward-Tordai equation [0]. This so-called "square-root-of-time-approach" works well for surfactants at low concentrations and short adsorption times, however, not for proteins. Protein molecules, when coming into contact with the interface, are subject to conformational changes. In particular at low bulk concentrations the process of self-assembly at the interface is rather slow, leaving enough space and time for molecular modifications. In particular at the water/oil interface the hydrophobic parts of the protein molecules have the tendency to penetrate into the hydrophobic oil phase and by this changing the molecular conformation. At low concentrations also the so-called induction time is observed, a period of time in which the progress of protein adsorption does not yet lead to an increase in the interfacial pressure.

A possibility to describe experimental data for proteins properly is to consider a mechanism that takes somehow the conformational changes of the adsorbed molecules into account. It appears realistic to assume that conformational changes lead to an increase in the surface activity. In the approach presented recently in [0], a combination of diffusional transport and an additional time process was proposed. Instead of the Volterra type integral equation proposed by Ward and Tordai [0], however, the diffusional transport problem given by a partial differential equation was solved numerically assuming the geometry of a large reservoir of an aqueous protein solution surrounding a spherical TD oil drop. More details of these mathematical issues are discussed in [0].

As an additional time-dependent process for the protein adsorption, it was proposed that the adsorption activity of the protein increases with the adsorbed amount. Typically, the adsorption activity coefficients in each state $b_{j}$ are assumed to be independent of the bulk concentration c, which is also true under dynamic conditions. However, it was assumed in [0] that at short adsorption times the adsorption activity coefficient is equal to a certain value $b_{0}$ and then increases with the adsorption time. This process should allow reflecting the structure formation by the protein and tetradecane molecules at the interface, supposing that some time is required for protein molecules to adapt to the conformation which they assume at the interface. The following relation for the change of the adsorption activity coefficient $b$ with time $\mathrm{t}$ was used: 


$$
\left.\begin{array}{ll}
\mathrm{b}(\mathrm{t})=\mathrm{b}_{0}(1+\mathrm{k} \times \mathrm{t}), & \text { for } \mathrm{t}<\mathrm{t}_{\text {max }} \\
\mathrm{b}_{\mathrm{m}}=\mathrm{b}_{0}\left(1+\mathrm{k} \times \mathrm{t}_{\max }\right), & \text { for } \mathrm{t} \geq \mathrm{t}_{\max }
\end{array}\right\}
$$

The increase of $b$ is limited by a maximum time $t_{\max }$, beyond which it remains constant equal to $b_{\mathrm{m}}$. Hence, in the moment the adsorption equilibrium has been reached, the adsorption activity coefficient should have the value obtained from fitting the entire experimental adsorption isotherm. The coefficient $\mathrm{k}$ can be called the kinetic constant. With this temporal dependence of the adsorption activity coefficient, Eq. (2) becomes:

$$
\mathrm{b}(\mathrm{t}) \cdot \mathrm{c}_{\mathrm{s} / \mathrm{s}}=\frac{\omega \Gamma_{1}}{(1-\theta)^{\omega_{1} / \omega}} \exp \left(-2 \mathrm{a} \frac{\omega_{1}}{\omega} \theta\right)
$$

It was demonstrated in [0] that the value of $b_{0}$ is remarkably lower than $b_{1}$ obtained from the fitting of surface pressure isotherm given by Eqs. (1) and (2). This value of $b_{0}$ appears actually to be rather close to the corresponding parameter obtained for BLG adsorbed at the W/A surface $[0,0]$. This fact allows speculating that in the beginning of the BLG adsorption layer formation process, i.e. at short adsorption times, the structure of the interfacial layers at the W/TD interface is similar to that at the W/A surface. On the contrary, the $b_{m}$ value was shown to be approximately equal to $b_{1}$.

In what follows, for the sake of brevity the model which is described by a diffusional transport and Eqs. (1) - (5) is referred to as the TIC model ("the model with time-independent adsorption activity coefficient"), while the model which implements Eqs. (1), (3) - (7) is called the TDC model ("the model with time-dependent adsorption activity coefficient"). This new model was first discussed in our recent manuscript [0] and used now for the data analysis of the dynamic interfacial pressure dependencies.

\section{Results and Discussion}

In [0] BLG was studied at the water/olive oil interface at $\mathrm{pH} 2.5$ and 7, and in [0] Benjamins presented the adsorption isotherms of several proteins at the water/air and different water/oil interfaces. To the best of our knowledge, however, there are so far no systematic investigations of the adsorption dynamics at a water/oil interface at different $\mathrm{pH}$ values of the aqueous phase. Only recently, Ulaganathan et al. [0] reported on the effect of $\mathrm{pH}$ on the adsorption kinetics and the surface pressure isotherm for BLG at the W/A surface. The experimental data for BLG at the W/TD interface for the three studied $\mathrm{pH}$ values $(3,5$ and 7$)$ are shown in Fig. 1(top). The three obtained isotherms $\Pi\left(\mathrm{C}_{\mathrm{BLG}}\right)$ show significant interfacial 
pressure values of $5 \mathrm{mN} / \mathrm{m}$ and more already at bulk concentrations of $\mathrm{C}_{\mathrm{BLG}}=10^{-10} \mathrm{~mol} / \mathrm{l}$, i.e. the isotherms start at much lower bulk concentrations as compared to the W/A surface (cf. [0]). Also the maximum interfacial pressure values of about $31 \mathrm{mN} / \mathrm{m}$ for $\mathrm{pH} 7$ and $36 \mathrm{mN} / \mathrm{m}$ for $\mathrm{pH} 3$ and $\mathrm{pH} 5$ are significantly higher as compared to about 20 to $25 \mathrm{mN} / \mathrm{m}$ measured at the W/A surface. However, the specific kinks in the isotherms, discussed in literature are the transition from monolayer adsorption to the formation of multilayers, appears at concentrations of around $10^{-7} \mathrm{~mol} / 1$ for $\mathrm{pH} 7$ and at almost $10^{-6} \mathrm{~mol} / 1$ for $\mathrm{pH} 3$ and $\mathrm{pH} 5$, which seems to be rather high concentrations. The possibility of the BLG molecules to protrude with their hydrophobic parts into the oil phase leads obviously to quite different structures of the interfacial layers, expressed by the isotherms.

Fig. 1 (top) also includes the dependencies calculated with a theoretical model derived and applied in previous papers $[0,0,0]$. The values of the model parameters used to obtain the best fit of the experimental data are listed in Table 1. The majority of them do not vary significantly with changes in the solution $\mathrm{pH}$ except the parameter $\mathrm{b}_{1}$. This parameter accounts for the surface activity of the protein molecules (line marked grey in Table 1). A similar situation was also observed in [0] for BLG adsorption layers at the W/A surface.

In Fig. 1 (bottom) the adsorbed amount of BLG is shown as calculated with the given model and the parameters listed in Table 1. For $\mathrm{pH} 5$ and 7 the total amounts of adsorbed BLG at the W/TD interface differ only slightly from each other, whereas smaller adsorbed amounts were obtained for layers obtained from solutions at $\mathrm{pH}$ 3. Only at very high bulk concentrations above $\mathrm{C}>10^{-6} \mathrm{~mol} / \mathrm{l}$ the adsorbed amount of BLG at $\mathrm{pH} 5$ becomes highest also at the W/TD interface.

On a first glance, the number of model parameters is tremendous. Note, however, that the first block of parameters refer to the thermodynamic model, which was developed earlier. It was applied successfully to a number of protein and polymer systems and the physical limits and independence of the parameters was discussed in great detail for example in [5]. The additional parameters, however, refer to the adsorption kinetics model, for which the thermodynamic equations (and the respective parameters) represent to base line, i.e. the target to which the kinetic process proceeds before the equilibrium state is reached. 
The dependencies shown in Fig. 2 were calculated using the optimum model parameters listed in Table 1. The major difference is that the critical point in the $\Pi$ dependence on $\Gamma$, after which the interfacial pressure changes only very slightly with the increasing adsorbed amount, appears at a rather large adsorbed amount $\left(\Gamma \approx 2.2 \mathrm{mg} / \mathrm{m}^{2}\right)$ for $\mathrm{pH} 5$, whereas for $\mathrm{pH} 3$ and 7 the critical points are comparable to each other, and appear at lower adsorption $(\Gamma \approx 1.9$ $\mathrm{mg} / \mathrm{m}^{2}$ ). Apparently, the stronger adsorption at $\mathrm{pH} 5$ cannot be explained by a smaller molar area as the data of $\omega$ dependence on $\Gamma$ in Fig. 2 show that the molar areas in the range around the critical points in the $\Pi$ dependence on $\Gamma$ are very close to each other for any studied $\mathrm{pH}$. Obviously, the average shape and orientation of the adsorbed BLG molecules control these dependencies. For the case of $\mathrm{pH}$, we conclude that a secondary adsorption layer is formed onto the primary monolayer. This is also in correlation with the adsorption dependence on concentration in Fig. 1, which show strong increase of the adsorbed amount at BLG concentrations higher than the critical point of ca. $4 \times 10^{-7} \mathrm{~mol} / 1$ on the interfacial pressure dependence on concentration.

In addition to the equilibrium state of adsorption of BLG at the W/TD interface at different solution $\mathrm{pH}$, the dynamics of the adsorption process was studied experimentally. These experiments were done at many concentrations and all three $\mathrm{pH}$ values 3,5 and 7 .

In Figs. 3a, 3b and 3c the dynamic interfacial tensions for one selected BLG solution at the studied $\mathrm{pH}$ values are shown. The BLG concentration $5 \times 10^{-8} \mathrm{~mol} / 1$ was selected such that it has been below the critical point for all three $\mathrm{pH}$ values as the model we want to apply was elaborated only for monolayer adsorption processes. Together with the experimental results, the values calculated using the two theoretical models described above, are shown in Figs. 3 (lines). 
The dashed lines correspond to a TIC model which assumes pure diffusion controlled adsorption kinetics, while solid lines correspond to the TDC model, i.e. a mixed model proposed recently in [0], which assumes the diffusion-governed transport of the BLG molecules in the solution bulk, and the additional dependence of surface activity coefficient on time as described by Eqs. (6) and (7). The model parameters for the data given in Figs. 3 are summarised in Table 2. As one can easily see, the new TDC model, assuming a physically reasonable diffusion coefficient of protein transport in the bulk in the range between $2.5 \times 10^{-10}$ and $3.5 \times 10^{-10} \mathrm{~m} / \mathrm{s}^{2}$, describes the experimental data very well (solid lines). In contrast, a mechanism based on a pure diffusional transport (dashed lines) cannot adequately reflect the experimental data. Also many more experiments performed in the whole concentration range below the critical point showed a similar kinetic behaviour, i.e. the dynamic interfacial tensions could be adequately described be the given TDC model.

The kinetic constants summarized in Table 2 demonstrate that the adsorption kinetics of BLG molecules at $\mathrm{pH} 5$ show the smallest $\mathrm{k}$ values, i.e. require the shortest time to adapt to the conformation required at the interface, while at $\mathrm{pH} 3$ and $\mathrm{pH} 7$ the re-conformation times are larger. The time $t_{\max }$ at which the interfacial layers approach a kind of quasi-equilibrium state is similar for all three studied $\mathrm{pH}$ values. As mentioned above, the interfacial activity coefficient $b_{m}$ obtained from the kinetic data is, averaged over all studied BLG concentrations (not shown here), very close to the corresponding value of $b_{1}$ obtained as the best fitting parameter for the equilibrium interfacial tension isotherm (see Table 1) shown as lines in Fig. 1 .

As mentioned above, we present here only the data for one selected concentration at the three selected $\mathrm{pH}$ values but not all studied systems as the dependencies look pretty much the same. The quality of fitting the data by the TDC model is very good and allows us to interpret the adsorption process at the W/TD interface more in terms of the molecular re-conformation and changes in the interfacial activity of the corresponding BLG molecules.

We finally consider qualitatively the phenomenon of the induction time which is a typical feature of protein adsorption processes. In [0] and [0] the induction time of BLG adsorbing at the W/A surface at different solution $\mathrm{pH}$ was discussed and it was demonstrated that it depends almost linearly on the BLG bulk concentration. For pH 3 the longest induction times of $t_{\text {ind }}>50000 \mathrm{~s}$ were found at bulk concentrations up to $5 \times 10^{-8} \mathrm{~mol} / 1$. The values of $t_{\text {ind }}$ for 
BLG solutions at pH 5 and 7 were lower. In particular for $\mathrm{pH} 7$ these times were almost one order of magnitude shorter. However, even at a bulk concentration of $10^{-6} \mathrm{~mol} / \mathrm{l}$ an induction time of about $100 \mathrm{~s}$ was still determined.

In contrast to the above, the induction times for BLG adsorbing from aqueous solutions at the W/TD interface at different $\mathrm{pH}$ are very short. Even at a bulk concentration of $2 \times 10^{-9} \mathrm{~mol} / \mathrm{l}$ the values of $t_{\text {ind }}$ are of the order of $100 \mathrm{~s}$, at all three $\mathrm{pH}$ values studied here (see Fig. 4). For larger BLG concentrations the inductions times are of the same order and only at very high concentrations $\left(>10^{-6} \mathrm{~mol} / \mathrm{l}\right)$ they get shorter. As it was discussed above, the adsorption of BLG at water/oil interfaces starts at concentrations much lower than those required for the W/A surface to change the surface pressure. This goes along with the induction times observed here. Even rather small amounts of adsorbed BLG molecules start to increase the interfacial pressure. The number of molecules adsorbed at the very low BLG concentration of $10^{-10} \mathrm{~mol} / \mathrm{l}$ is already quite large and obviously sufficient to change the interfacial tension (cf. Fig. 2).

\section{Conclusions}

The interfacial tension isotherms determined for BLG at the solution $\mathrm{pH}$ of 3, 5 and 7 can be well described by a thermodynamic TIC model developed earlier in [0]. All model parameters obtained by fitting the theory to the experimental data are more or less identical for the three $\mathrm{pH}$ values, except for the surface activity parameter $\mathrm{b}$, which increases with the $\mathrm{pH}$. A striking difference to the adsorption of BLG at the W/A surface is that the interfacial pressure for the solutions at the W/TD interface starts to increase at concentrations many orders of magnitude lower. Moreover, the isotherms at the W/A surface are much steeper than the corresponding isotherms at the W/TD interface. While the isotherms at the W/A surface reach the critical point of secondary layer formation rather quickly, at the W/TD interface the critical points are reached at much higher protein bulk concentrations. In addition, the interfacial pressure values $\Pi^{*}$ at these critical concentrations are much larger by almost a factor of three. Hence, one could conclude that the adsorbed amounts at the W/TD interface should be much larger. However, the calculated adsorption values shown in Fig. 2 are similar to those observed for example in [0] or [0] for the same BLG at the W/A surface at $\mathrm{pH} 7$. Hence, it is not the total 
adsorbed amount leading to the high interfacial pressure values but the interfacial structure resulting from a strong interaction between the hydrophobic parts of the adsorbed protein molecules and the TD.

The new mixed (TDC) model proposed in [0] combined with a transport of the adsorbing molecules in the solution bulk by diffusion describes the dynamic interfacial tension data very well. In contrast, a pure diffusional transport cannot properly reproduce the experimental dependencies. A conformational change of the BLG molecules is considered when coming in contact with the hydrophobic tetradecane phase at the interface. The consequence of this changed conformation is expressed through the adsorption activity constant in the corresponding equation of state. The rate constant $\mathrm{k}$ obtained by a best fit of the results using the diffusion controlled adsorption model differs depending on the BLG bulk concentration and solution $\mathrm{pH}$. The kinetic constant $\mathrm{k}$ in Eq. (5) is the smallest for BLG solutions at $\mathrm{pH} 5$ which physically means that the protein molecules change their conformation at the interface to the smallest extend. In contrast, at $\mathrm{pH} 3$ the conformational changes are the largest.

To our surprise, the induction time observed for BLG at the W/TD interface are very short and do not significantly depend on the solution $\mathrm{pH}$. Even at a very low bulk concentration of $5 \times 10^{-9} \mathrm{~mol} / \mathrm{l}$ the induction time is of the order of $100 \mathrm{~s}$ for the three studied $\mathrm{pH}$ values and decreases only at very high concentrations. This is in contrast to the findings for the W/A surface where we found a strong dependence of $t_{\text {ind }}$ on the BLG concentration and the $\mathrm{pH}$ of the aqueous solution. This phenomenon seems to be caused by the same reason as the remarkable change of the interfacial tensions at very low BLG bulk concentrations due to the strong interaction between protein and TD molecules at the interface.

\section{Acknowledgements}

The authors are grateful for the support by the COST actions MP1106 and CM1101. 
References

[1] E. Dickinson, Adsorbed protein layers at fluid interfaces: interactions, structure and surface rheology, Colloids Surface B 15 (1999) 161-176.

[2] J.M. Ruso, A. Pineiro, Proteins in solutions and at interfaces: Methods and Applications in Biotechnology and Material Science, In: Surface and Interfacial Chemistry series, P. Somasundaran, N. Garti, Eds. John Wiley \& Sons Inc., Hoboken, NJ, 2012.

[3] B.C. Tripp, J.J. Magda, J.D. Andrade, Adsorption of globular proteins at the air/water interface as measured via dynamic surface tension: Concentration dependence, mass-transfer considerations, and adsorption kinetics, J. Colloid Interface Sci. 173 (1995) 16-27.

[4] J.M. Álvarez Gómez, J.M. Rodríguez Patino, Formulation engineering of food model foams containing diglycerol esters and $\beta$-lactoglobulin, Ind. Eng. Chem. Res. 45 (2006) 7510 7519.

[5] G. Gochev, I. Retzlaff, E.V. Aksenenko, V.B. Fainerman, R. Miller, Adsorption isotherm and equation of state for $\beta$-Lactoglobulin layers at the air/water surface, Colloids Surfaces A 422 (2013) 33-38.

[6] V. Ulaganathan, I. Retzlaff, J.Y. Won, G. Gochev, C. Gehin-Delval, M.E. Leser, D.Z. Gunes, B.A. Noskov, R. Miller, $\beta$-lactoglobulin adsorption layers at the water/air surface:

1. Adsorption kinetics and surface pressure isotherm: effect of $\mathrm{pH}$ and ionic strength, COLSUA-D-15-02002, decision in progress . 
[7] S.A. Roberts, I.W. Kellaway, K.M.G. Taylor, B. Warburton, K. Peters, Combined surface pressure-interfacial shear rheology study of the effect of $\mathrm{pH}$ on the adsorption of proteins at the air-water interface, Langmuir 21 (2005) 7342-7348.

[8] J.P. Davis, E.A. Foegeding, F.K. Hansen, Electrostatic effects on the yield stress of whey protein isolate foams. Colloids Surfaces B 34 (2004) 13-23.

[9] V.P. Ruíz-Henestrosa, C.C. Sánchez, M.d.M.Y. Escobar, J.J.P. Jimenez, F.M. Rodríguez, J.M.R. Patino.; Interfacial and foaming characteristics of soy globulins as a function of $\mathrm{pH}$ and ionic strength. Colloids and Surfaces A 309 (2007) 202-215.

[10] T. Sengupta, S. Damodaran, Role of dispersion interactions in the adsorption of proteins at oil-water and air-water interfaces. Langmuir, 14 (1998) 6457-6469.

[11] R. Douillard, M., Daoud, J. Lefebvre, C. Minier, G. Lecannu, J. Coutret, State equation of $\beta$-casein at the air/water interface, J. Colloid Interface Sci., 163 (1994) 277-288.

[12] G. Gochev, E.V. Aksenenko, V.B. Fainerman, R. Miller, $\quad \beta$-lactoglobulin adsorption layers at the water/air surface: 3 . Theoretical modelling: effect of $\mathrm{pH}$, submitted to Langmuir.

[13] V. Ulaganathan, I. Retzlaff, J.Y. Won, G. Gochev, C. Gehin-Delval, M. Leser, B.A. Noskov, R. Miller, $\beta$-lactoglobulin adsorption layers at the water/air surface: 2. Dilational rheology: effect of $\mathrm{pH}$ and ionic strength, to be submitted to Colloids Surfaces A.

[14] V. Ulaganathan, G. Gochev, C. Gehin-Delval, M.E. Leser, D.Z. Gunes, R. Miller, Effect of $\mathrm{pH}$ and salt concentration on rising air bubbles in $\beta$-lactoglobulin solutions, Colloids Surfaces A, submitted to Colloids Surfaces A. 
[15] K.B. Song, S. Damodaran, Influence of electrostatic forces on the adsorption of succinylated $\beta$-lactoglobulin at the air-water interface, Langmuir 7 (1991) 2737-2742.

[16] J.Y. Won, G.G. Gochev, V. Ulaganathan, J. Krägel, E.V. Aksenenko, V.B. Fainerman, R. Miller,;Mixed adsorption mechanism for the kinetics of BLG interfacial layer formation at the solution/tetradecane interface, submitted to Colloids Surfaces A (SI for ECIS).

[17] J. Toro-Sierra, A. Tolkach, U. Kulozik, Fractionation of $\alpha$-lactalbumin and $\beta$ lactoglobulin from whey protein isolate using selective thermal aggregation, an optimized membrane separation procedure and resolubilization techniques at pilot plant scale, Food Bioprocess Technol. 6 (2013) 1032-1043. .

[18] D.C. Clark, F. Husband, P. Wilde, M. Cornec, R. Miller, L. Krägel, R. Wüstneck, Evidence of extraneous surfactant adsorption altering adsorbed layer properties of $\beta$ lactoglobulin, J. Chem. Soc., Faraday Trans. 91 (1995) 1991-1996.

[19] G. Loglio, P. Pandolfini, R. Miller, A.V. Makievski, F. Ravera, M. Ferrari, L. Liggieri, Drop and bubble shape analysis as tool for dilational rheology studies of interfacial layers, in: D. Möbius, R. Miller (Eds.), in: Novel Methods to Study Interfacial Layers, Studies in Interface Science, vol. 11, Elsevier, Amsterdam, 2001, p. 439.

[20] D.E. Graham, M.C. Philips, Proteins at liquid interfaces I. Kinetics of adsorption and surface denaturation, J. Colloid Interface Sci. 70 (1979) 403-414.

[21] D.E. Graham, M.C. Philips, Proteins at liquid interfaces II. Adsorption isotherms, J. Colloid Interface Sci. 70 (1979) 415-426. 
[22] D.E. Graham, M.C. Philips, Proteins at liquid interfaces III. Molecular structure of adsorbed films, J. Colloid Interface Sci. 70 (1979) 427-439.

[23] S.J. Singer, Note on an equation of state for linear macromolecules in monolayers, J. Chem. Phys. 16 (1948) 872-876.

[24] P. Joos, G. Serrien, The principle of Braun-Le Châtelier at surfaces, J. Colloid Interface Sci. 145 (1991) 291-294.

[25] R. Wüstneck, V.B. Fainerman, E.V. Aksenenko, Cs. Kotsmar, V. Pradines, J. Krägel, R. Miller, Surface dilatational behavior of $\beta$-casein at the solution/air interface at different $\mathrm{pH}$ values, Colloids and Surfaces A, 404 (2012) 17-24.

[26] A.F.H. Ward, L. Tordai, Time-dependence of boundary tensions of solutions. I. The role of diffusion in time-effects. J. Phys. Chem. 14 (1946) 453-461.

[27] J. Maldonado-Valderrama, P.J. Wilde, V.J. Morris, V.B. Fainerman, R. Miller, The effect of gastric conditions on $\beta$-lactoglobulin interfacial networks: Influence of the oil phase on protein structure, Langmuir, 26 (2010) 15901-15908.

[28] J. Benjamins, Static and dynamic properties of proteins adsorbed at liquid interfaces. $\mathrm{PhD}$ thesis, Wageningen, 2000.

[29] J. Krägel, M. O’Neill, A.V. Makievski, M. Michel, M.E. Leser, R. Miller, Dynamics of mixed protein-surfactant layers adsorbed at the water/air or water/oil interface. Colloids Surfaces B 31 (2003) 107-114. 
Fig. 1 Surface properties of $10 \mathrm{mM}$ buffered BLG solutions with different $\mathrm{pH}$ values at the W/TD interface. Top, surface pressure isotherm; bottom, adsorption isotherm. Symbols, experimental points; Lines: best fit of the results calculated using the model described in $[0,0,0]$ to the experimental data. $\circ$, red solid line, $\mathrm{pH} \mathrm{3;} \Delta$, black dashed line, $\mathrm{pH} 5$; $\square$, blue dotted line, $\mathrm{pH} 7$.
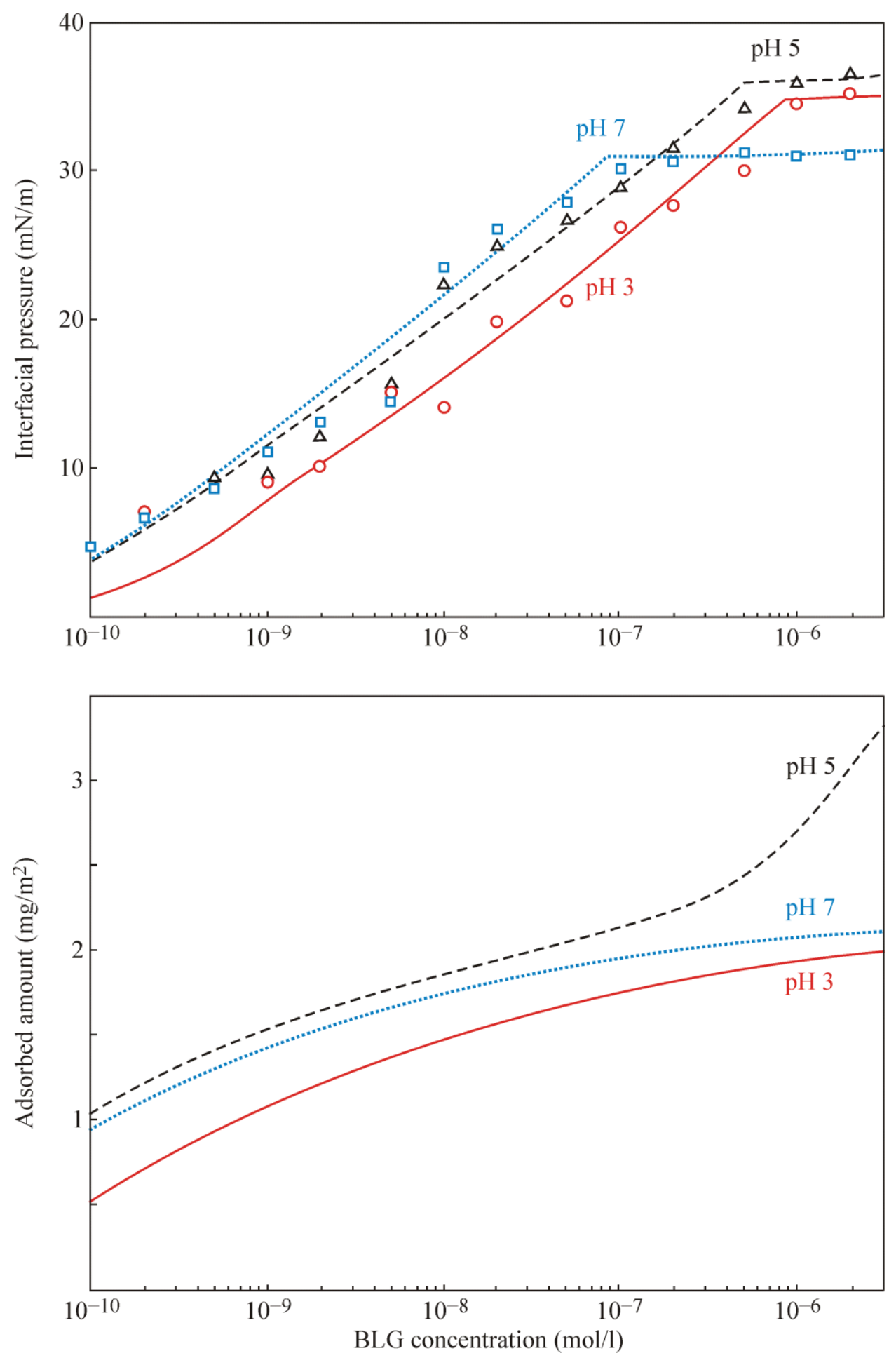
Fig. 2 Calculated dependences of the interfacial pressure (top) and the area per molecule (bottom) on the adsorbed amount of BLG at the three selected $\mathrm{pH}$ values using the parameter values listed in Table 1. Red solid line, $\mathrm{pH}$ 3; black dashed line, $\mathrm{pH}$ 5; blue dotted line, $\mathrm{pH} 7$.
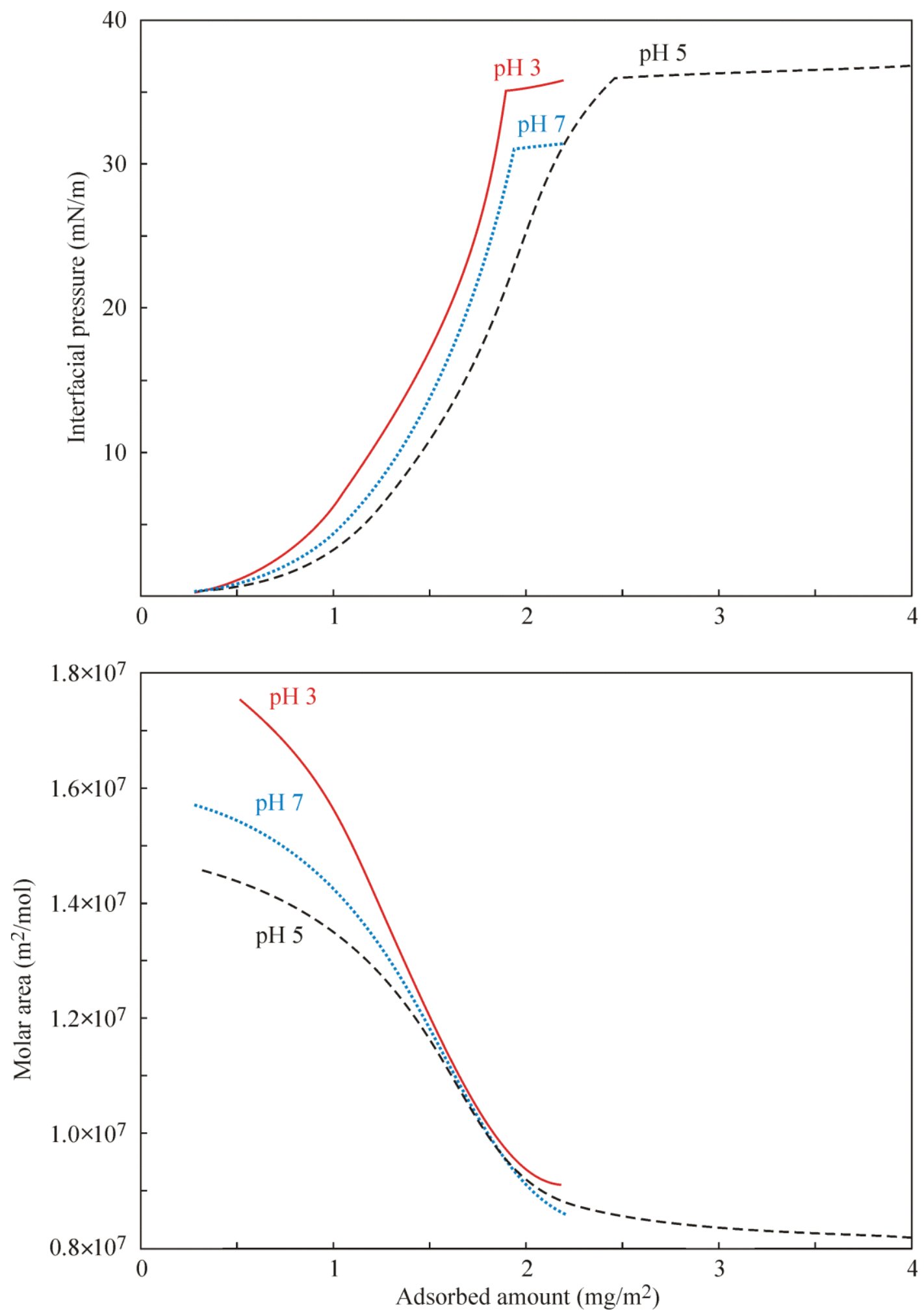
Fig. 3 Dynamic interfacial tensions $\gamma(\mathrm{t})$ for BLG solutions with a concentration of $5 \times 10^{-8}$ mol/1 at the W/TD interface: (a), (b) and (c), pH 3, pH 5 and $\mathrm{pH} 7$, respectively. Symbols, experimental data. Dashed lines, calculations using TIC model; Solid lines, calculations using TDC model which implies additional dependence of surface activity coefficient on time.

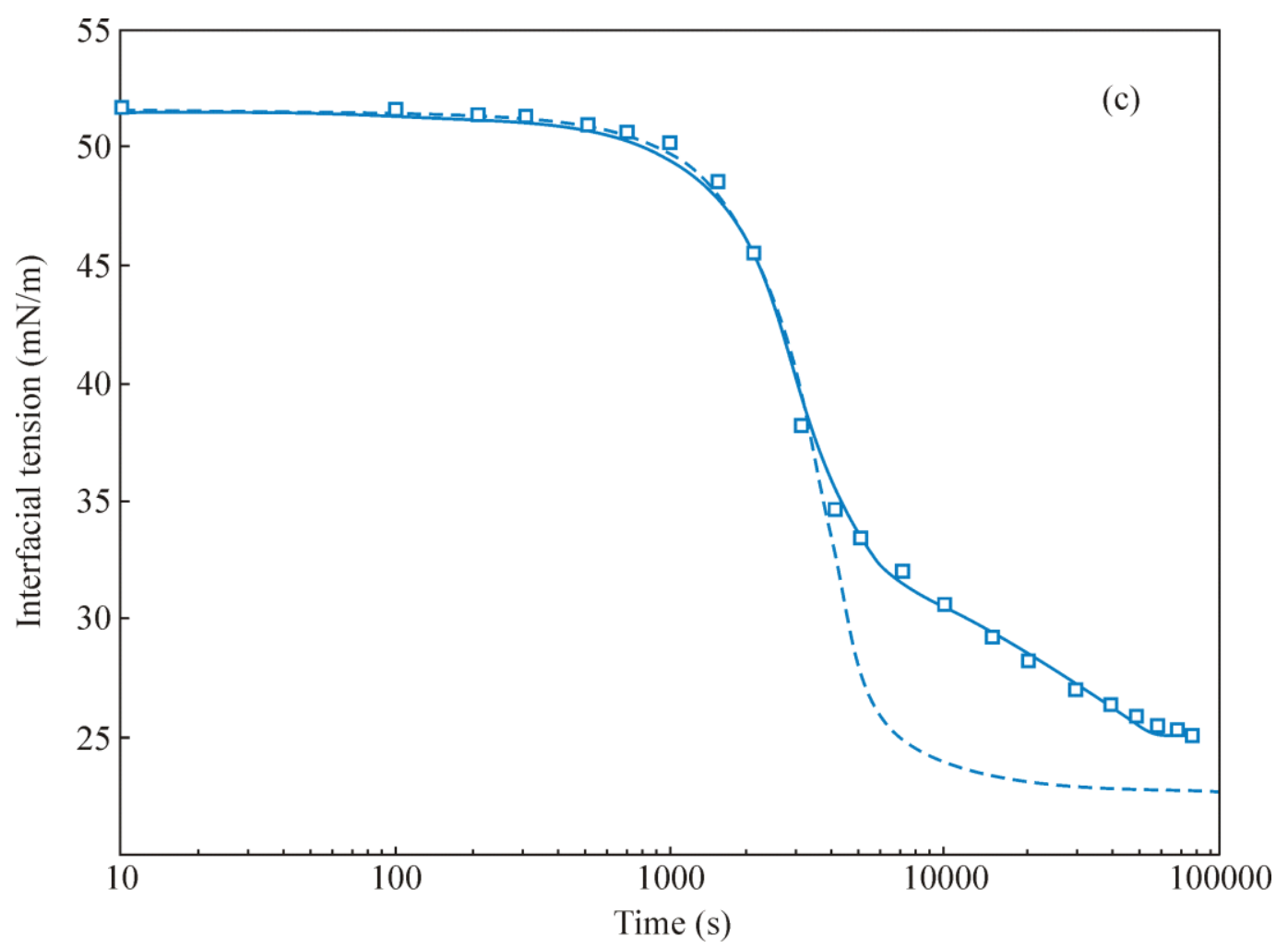


Fig. 4 Dynamic interfacial tension of BLG solution with concentration $2 \times 10^{-9} \mathrm{~mol} / 1$ (filled symbols) and $5 \times 10^{-8} \mathrm{~mol} / \mathrm{l}$ (open symbols), at three different $\mathrm{pH}$ values: $\mathrm{pH} 3(\circ, \bullet), \mathrm{pH} 5(\Delta$, $\boldsymbol{\Delta})$, and $\mathrm{pH} 7(\square, \square)$; lines are guides for eye.

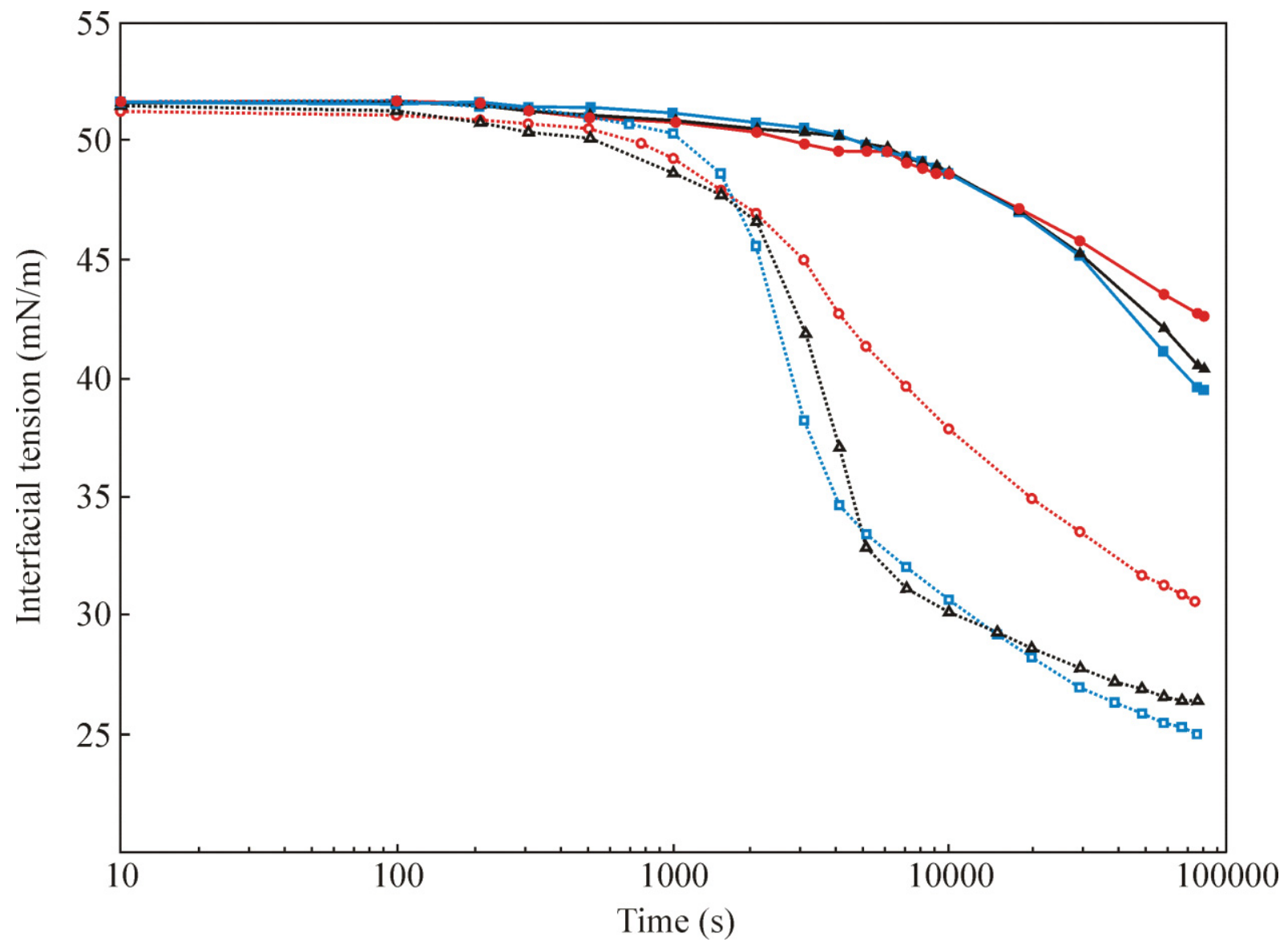

Table 1. Summary of the values of the model parameter used to obtain the best fit between the theoretical model and the experimental data of BLG adsorption layers at the W/TD interface. 


\begin{tabular}{|l|c|c|c|}
\hline Parameters & $\mathrm{pH} \mathrm{3}$ & $\mathrm{pH} \mathrm{5}$ & $\mathrm{pH} \mathrm{7}$ \\
\hline$a$ & 0 & 0 & 0 \\
\hline$\alpha$ & 1.2 & 1.2 & 1.0 \\
\hline$\omega_{0}\left[10^{5} \mathrm{~m}^{2} / \mathrm{mol}\right]$ & 4.2 & 4.7 & 4.2 \\
\hline$\omega_{1}\left[10^{6} \mathrm{~m}^{2} / \mathrm{mol}\right]$ & 8.2 & 7.5 & 7.9 \\
\hline$\omega_{\mathrm{m}}\left[10^{7} \mathrm{~m}^{2} / \mathrm{mol}\right]$ & 2.5 & 2.0 & 2.2 \\
\hline $\mathrm{n}_{\mathrm{a}}$ & 38 & 22 & 48 \\
\hline$\Pi^{*} \mathrm{mN} / \mathrm{m}$ & 35 & 36 & 31 \\
\hline $\mathrm{b}_{1}\left[10^{5} \mathrm{~m}^{3} / \mathrm{mol}\right]$ & 1.0 & 6.0 & 4.8 \\
\hline $\mathrm{b}_{\mathrm{X}}\left[10^{1} \mathrm{~m}^{3} / \mathrm{mol}\right]$ & 5 & 340 & 2 \\
\hline $\mathrm{m}$ & 2 & 2 & 2 \\
\hline
\end{tabular}

Table 2. Parameters values in the adsorption activity equation $\mathrm{b}_{\mathrm{m}}=\mathrm{b}_{0} \cdot\left(1+\mathrm{k} \times \mathrm{t}_{\max }\right)$ for $\mathrm{a}$ selected BLG concentration of $5 \times 10^{-8} \mathrm{~mol} / \mathrm{l}$ at $\mathrm{pH} 3,5$ and 7 .

\begin{tabular}{|l|c|c|c|}
\hline \multicolumn{1}{|c|}{ Parameters } & $\mathrm{pH} \mathrm{3}$ & $\mathrm{pH} \mathrm{5}$ & $\mathrm{pH} \mathrm{7}$ \\
\hline $\mathrm{b}_{0}, 10^{4}\left[\mathrm{~m}^{3} / \mathrm{mol}\right]$ & 0.1 & 15 & 6.0 \\
\hline $\mathrm{k}, 10^{-5}[1 / \mathrm{s}]$ & 100 & 3.2 & 6.5 \\
\hline $\mathrm{t}_{\max }, 10^{4}[\mathrm{~s}]$ & 6.0 & 5.5 & 5.5 \\
\hline $\mathrm{b}_{\mathrm{m}}, 10^{5}\left[\mathrm{~m}^{3} / \mathrm{mol}\right]$ & 0.61 & 4.1 & 2.7 \\
\hline
\end{tabular}

